\title{
Canada lags US in adoption of e-prescribing
}

E -prescribing is "inextricably tied" to the implementation of electronic health records, which is proceeding across the country, "albeit at a very slow pace," says the Health Council of Canada, a government-funded, non-profit agency that was created to advise Canadians about the effectiveness and sustainability of the health care system.

There are no legal barriers preventing Canadian doctors from writing prescriptions electronically and sending them digitally to pharmacies, says John Abbott, the Health Council's chief executive officer. But privacy considerations prevent most physicians from using common word processing software and email, and pharmacies are not yet connected to clinics, hospitals and doctors offices in the kind of secure electronic network and drug database that e-prescribing will ultimately require.

E-prescribing on its own will be of minimal value without a full electronic patient record for each patient across Canada, Abbott says. "You need to tie in the prescription information with the physician's decision and record. That's one of the challenges and barriers, we feel, why e-prescribing has not advanced to the degree one would expect at this point in time."

The Canadian Medical Association (CMA) is advocating electronic medical records that contain a drug prescription module for physicians' offices and primary care settings. As in the United States model, the electronic drug program would deliver alerts warning of potential adverse effects when the medication a doctor has chosen interacts with other medications the patient is taking. The e-prescribing program would also flag cheaper generic options and other alternatives, says Bill Pascal, the CMA's Chief Technology Officer. The doctor would always have the power to override the program.

'It's giving real-time information to the physician to help that individual make sure the drug script or medication

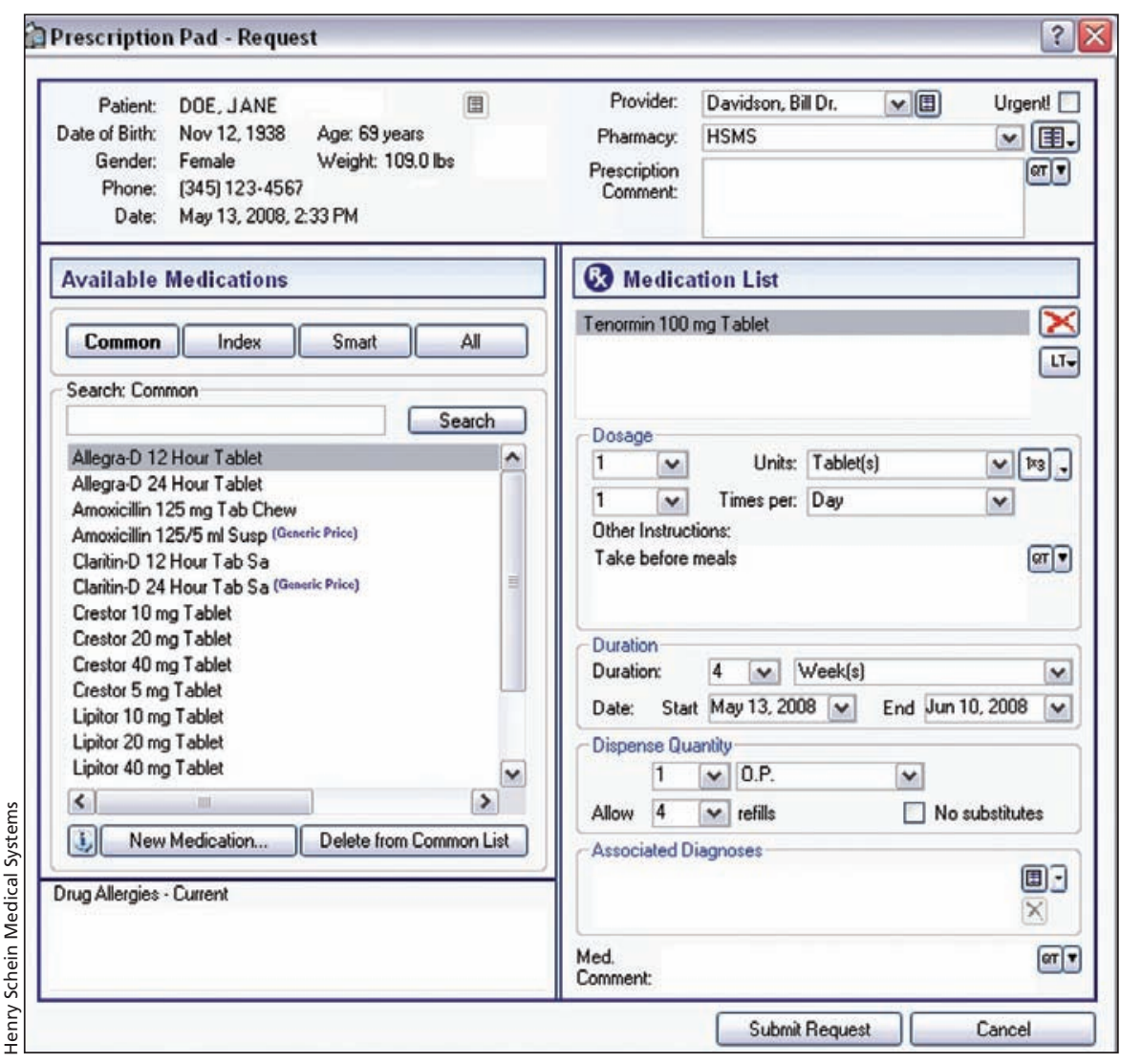

A sample electronic prescription pad from MicroMD EMR v6.0.

program they are recommending to the patient is the best it can be," Pascal says.

There is no initiative in Canada on the scale of the recent US\$19-billion plan announced by US President Barack Obama to promote more e-prescribing and digital record keeping, (CMAJ 2009;180[8]:806).

Currently, British Columbia, Saskatchewan, Ontario and Nova Scotia have all negotiated agreements to support physicians to bring electronic medical records into their offices. The provinces pay about $70 \%$ of the cost of upgrading doctors' computer systems and offices, while the physicians pay the remaining $30 \%$.

In total, about $26 \%$ of all doctors in Canada, excluding surgeons, are already using electronic medical records, says Pascal.
Some of those doctors are already entering prescriptions electronically into a patient's electronic medical record and are handing a printed prescription to patients, he adds. But most are not yet sending the prescriptions to pharmacies electronically, because the pharmacies are not yet connected to the physicians' offices. In addition, the provinces have all agreed to build drug databases, but they do not yet exist in most provinces.

At the Algoma District Medical Group in Sault St. Marie, Ontario, Dr. Lewis O'Brien is engaged in a pilot project designed to identify e-prescribing issues. Currently, O'Brien writes prescriptions electronically on a "great" system integrated into electronic medical records that checks for allergies and interactions against his patient's drug list. Although he prints the pre- 
scriptions, he does not yet send them to pharmacies electronically.

When the day comes that a doctor can enter a prescription directly into a drug store's system, "at least they will have a legible prescription and access to the doc's list of meds for that patient," O'Brien says. "So it's coming, slowly but surely."

Ultimately, a centralized drug database will store a record of every prescription and whether or not it has been filled, which will enable doctors to follow up with patients.
The database will give the provinces the capability to assess prescription trends, to track what brands and what generics are being prescribed, and to assist in managing costs, says Pascal. British Columbia already has a drug database, while Alberta has built one and is populating it with information.

Pascal predicts it will be "3 or 4 years" before Canadian doctors and patients see the full benefits of e-prescribing.

The Health Council is also confident that e-prescribing will eventually be widespread, as part of electronic medical records, across the country. But to get there will require an investment that Pascal puts "in the hundreds of millions of dollars."

Abbott agrees. "We feel that the pace needs to be picked up, and could be picked up, but it will require an investment of new dollars by governments, federally, provincially and territorially." - Laura Eggertson, CMAJ

DOI:10.1503/cmaj.090529 